\title{
Sodium iron EDTA and ascorbic acid, but not polyphenol oxidase treatment, counteract the strong inhibitory effect of polyphenols from brown sorghum on the absorption of fortification iron in young women
}

\author{
Colin I. Cercamondi*, Ines M. Egli, Christophe Zeder and Richard F. Hurrell \\ Laboratory of Human Nutrition, Institute of Food, Nutrition and Health, ETH Zurich, Zurich, Switzerland \\ (Submitted 9 April 2013 - Final revision received 11 July 2013 - Accepted 16 July 2013 - First published online 20 August 2013)
}

\begin{abstract}
In addition to phytate, polyphenols (PP) might contribute to low Fe bioavailability from sorghum-based foods. To investigate the inhibitory effects of sorghum PP on Fe absorption and the potential enhancing effects of ascorbic acid (AA), NaFeEDTA and the PP oxidase enzyme laccase, we carried out three Fe absorption studies in fifty young women consuming dephytinised Fe-fortified test meals based on white and brown sorghum varieties with different PP concentrations. Fe absorption was measured as the incorporation of stable Fe isotopes into erythrocytes. In study 1 , Fe absorption from meals with $17 \mathrm{mg} \mathrm{PP}(8.5 \%)$ was higher than that from meals with $73 \mathrm{mg}$ PP (3.2\%) and $167 \mathrm{mg}$ PP $(2.7 \% ; P<0.001)$. Fe absorption from meals containing 73 and $167 \mathrm{mg}$ PP did not differ $(P=0.9)$. In study 2 , Fe absorption from NaFeEDTA-fortified meals (167 mg PP) was higher than that from the same meals fortified with $\mathrm{FeSO}_{4}(4 \cdot 6 v .2 \cdot 7 \% ; P<0 \cdot 001)$, but still it was lower than that from FeSO 4 -fortified meals with $17 \mathrm{mg}$ PP $(10.7 \% ; P<0.001)$. In study 3 , laccase treatment decreased the levels of PP from 167 to $42 \mathrm{mg}$, but it did not improve absorption compared with that from meals with $167 \mathrm{mg}$ PP $(4.8 v .4 .6 \% ; P=0 \cdot 4)$, whereas adding AA increased absorption to $13.6 \%(P<0 \cdot 001)$. These findings suggest that PP from brown sorghum contribute to low Fe bioavailability from sorghum foods and that AA and, to a lesser extent, NaFeEDTA, but not laccase, have the potential to overcome the inhibitory effect of PP and improve Fe absorption from sorghum foods.
\end{abstract}

Key words: Iron absorption: Sorghum: Polyphenols: Iron fortification

Fe deficiency (ID) is the most prevalent micronutrient deficiency worldwide, affecting principally children aged $<5$ years and women of childbearing age living in the poorer communities of the developing world ${ }^{(1)}$. ID has major negative impacts on health and mental development, and in pregnancy, it contributes to the risk of severe anaemia, which is associated with higher maternal morbidity and mortality ${ }^{(2,3)}$. The aetiology of ID in developing countries is multifactorial, but the major contributors are low dietary $\mathrm{Fe}$ bioavailability and intake from monotonous diets based on cereal staple foods such as sorghum ${ }^{(4)}$.

Sorghum (Sorghum bicolor (L.) Moench) is the world's fifth most important cereal in terms of production and a staple food in sub-Saharan Africa and India ${ }^{(5)}$, where it is a major source of energy, proteins and micronutrients for millions of people ${ }^{(6)}$. The colour of sorghum grain varies among different varieties. White grains are preferably used for the preparation of foods such as porridge, baked products and couscous. Red and brown grains are also widely used for the preparation of porridges and/or pastes, but, in addition, they are used for the preparation of fermented and non-fermented local beverages $^{(7-9)}$. Thin sorghum porridges, which are occasionally fermented, are popular complementary foods throughout sub-Saharan Africa ${ }^{(10-13)}$.

The native Fe concentration of sorghum has been reported to be about $3-5 \mathrm{mg} / 100 \mathrm{~g}$ flour ${ }^{(14)}$. Fe bioavailability from sorghum-based diets is expected to be low due to high amounts of phytic acid (PA) in the grains ${ }^{(15,16)}$ and high amounts of polyphenols (PP) in some coloured varieties ${ }^{(7,17)}$. Both PA and PP can be potent Fe absorption inhibitors, forming nonabsorbable complexes in the gut lumen ${ }^{(18,19)}$. The inhibitory effect of PP varies according to their structure ${ }^{(19-21)}$. The total PP concentration of sorghum depends not only on genetic factors such as seed colour and pericarp thickness, but also on environmental factors such as growing conditions ${ }^{(22)}$. Sorghum varieties with red and brown colours have higher average PP concentrations (1.35\%) than light-coloured sorghum grains $(0.40 \%)^{(7)}$; the colour is mainly attributable to PP called deoxyanthocyanidins ${ }^{(23,24)}$.

Fortification of cereal flours with Fe is the main strategy to combat ID in communities where cereals are the staple food. Unlike wheat flour, sorghum flour is usually not milled

Abbreviations: AA, ascorbic acid; CRP, C-reactive protein; ID, Fe deficiency; PA, phytic acid; PF, plasma ferritin; PP, polyphenols; PPO, polyphenol oxidase. 
centrally and fortification at the community level can be problematic. Therefore, Fe fortification of sorghum flour is still in the early stages, and knowledge on appropriate $\mathrm{Fe}$ compounds for sorghum fortification is scarce. Cereals such as sorghum are particularly difficult to fortify with $\mathrm{Fe}$, since they contain significant amounts of both $\mathrm{PA}$ and $\mathrm{PP}^{(25)}$. NaFeEDTA is recommended as a fortificant in cereals containing high amounts of $\mathrm{PA}^{(26)}$; however, results from previous studies in tea have raised questions about its ability to overcome the inhibitory effect of $\mathrm{PP}^{(27)}$. The usefulness of NaFeEDTA in the presence of PP from other sources is unknown. Other approaches to enhance Fe bioavailability from sorghum flour would be the addition of ascorbic acid (AA), a well-known Fe absorption enhancer ${ }^{(28)}$, and the enzymatic reduction of inhibitory PP by a PP oxidase (PPO). Phytase has been used in a similar way to degrade PA and increase Fe absorption from cereal meals ${ }^{(25)}$.

Herein, we report three stable isotope absorption studies carried out in young women consuming dephytinised Fe-fortified sorghum porridges made from white and brown sorghum flours containing different concentrations of PP. The studies investigated a potential dose-dependent inhibitory effect of sorghum PP on Fe absorption and the ability of NaFeEDTA, AA and laccase to overcome the inhibitory effect.

\section{Methods}

\section{Participants}

A total of fifty apparently healthy, non-pregnant, non-lactating women aged between 18 and 40 years, with a normal BMI $\left(18.5-25 \mathrm{~kg} / \mathrm{m}^{2}\right)$ and a body weight below $65 \mathrm{~kg}$, were recruited from the student and staff population of ETH Zurich, Switzerland. The participants were randomly allocated to three Fe absorption studies, with sixteen or eighteen participants per study. Women with a known metabolic, chronic or gastrointestinal disease, as well as those on long-term medication (except oral contraceptives), were excluded from participating. Intake of vitamin and/or mineral supplements was not allowed during and 2 weeks before the studies. Women who had donated blood or experienced substantial blood loss within 4 months of the start of the study were not recruited. The study was carried out according to the guidelines laid down in the Declaration of Helsinki, and all procedures involving human subjects were approved by the ethical committee at ETH Zurich, Switzerland. All the participants provided written informed consent.

\section{Study design}

Using a randomised cross-over design with each participant serving as her own control, three Fe absorption studies were carried out. In study 1, the influence of different amounts of sorghum PP on Fe absorption was investigated using white and brown sorghum flours and a mixture of both. In study 2 , the potential of NaFeEDTA to overcome the inhibitory effect of sorghum PP on Fe absorption was investigated, and in study 3 , the potential of AA addition and PPO pre-treatment of sorghum meals to overcome the inhibitory effect was investigated. In each study, three differently labelled sorghum test meals were given to the participants on three consecutive days in a randomised fashion (Fig. 1). Fe absorption was determined using a stable isotope technique measuring the incorporation of isotopic Fe labels into erythrocytes $14 \mathrm{~d}$ after the consumption of the third test meal ${ }^{(29)}$.

On day 0 , body weight and height were measured, and the first blood sample was collected for Fe status ( $\mathrm{Hb}$; plasma ferritin, PF) and inflammation (C-reactive protein, CRP) measurements. On day 1 , the first labelled test meal was given in two servings with an interval of minimum $3 \mathrm{~h}$. On days 2 and 3 , the second and third test meals were given after an overnight fast following the same procedure. The test meals were given under strictly standardised conditions and under close supervision of the investigators. The complete intake of isotopically labelled meals was ensured by rinsing the test meal bowl twice with $10 \mathrm{ml}$ of high-purity water $(18 \mathrm{~mol} / \mathrm{l})$ after consumption and by letting the participants consume the rinsing water. No intake of food and fluids was allowed between the two meals and for $3 \mathrm{~h}$ after the consumption of the second meal. In all the three studies, the servings of the three different test meals were labelled with $2 \mathrm{mg}{ }^{54} \mathrm{Fe},{ }^{57} \mathrm{Fe}$ or ${ }^{58} \mathrm{Fe}$. A second blood sample was drawn for Fe isotopic analysis $14 \mathrm{~d}$ after the consumption of the third test meal (day 17).

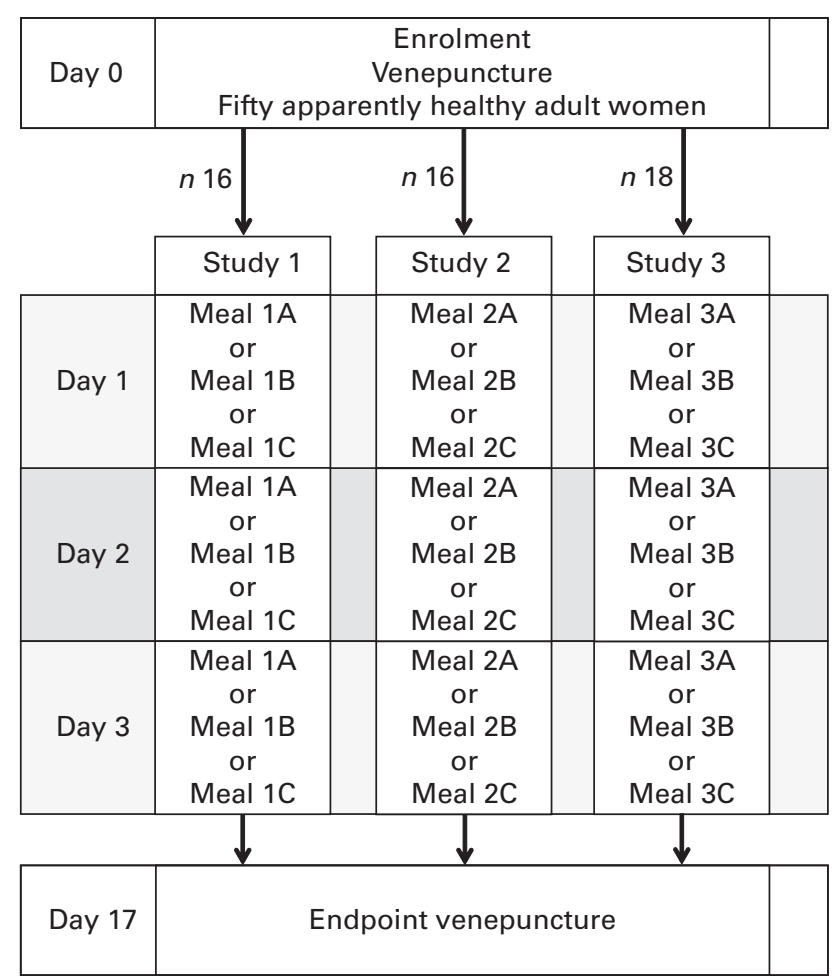

Fig. 1. Schematic diagram of the study protocol. Meals $1 \mathrm{~A}$ and $2 \mathrm{~A}$ are low-polyphenol (PP) sorghum porridges fortified with $\mathrm{FeSO}_{4}$; meal $1 \mathrm{~B}$ is a medium-PP sorghum porridge fortified with $\mathrm{FeSO}_{4}$; meals $1 \mathrm{C}, 2 \mathrm{~B}$ and $3 \mathrm{~A}$ are high-PP sorghum porridges fortified with $\mathrm{FeSO}_{4}$; meal $2 \mathrm{C}$ is a high-PP sorghum porridge fortified with NaFeEDTA; meal $3 \mathrm{~B}$ is a high-PP sorghum porridge fortified with ascorbic acid and $\mathrm{FeSO}_{4}$; meal $3 \mathrm{C}$ is a reduced-PP sorghum porridge pre-treated with laccase and fortified with $\mathrm{FeSO}_{4}$. 


\section{Test meals}

A white sorghum variety (CSM 485; Kossa) and a brown sorghum variety (ICSV 1001; Framida) from Mali and Burkina Faso, respectively, were used to prepare the test meals with low, medium and high PP concentrations. White sorghum was decorticated in Mali using an abrasive dehulling device (TADD; Venable Machine Works). Brown sorghum was decorticated in France using an abrasive laboratory-scale decorticator (DMS 500; Electra). Both varieties were washed before decortication, and an extraction rate of $86-90 \%$ was obtained. After decortication, they were milled in Switzerland using a centrifugal mill (Retsch) equipped with a Ti sieve to avoid Fe contamination. Flours were prepared in bulk and used for the three studies.

In study 1 , test meals were based on the white sorghum flour labelled with $2 \mathrm{mg}{ }^{54} \mathrm{Fe}$ as $\mathrm{FeSO}_{4}(1 \mathrm{~A})$, brown sorghum flour labelled with $2 \mathrm{mg}{ }^{58} \mathrm{Fe}$ as $\mathrm{FeSO}_{4}$ (1C) and a 1:1 mixture of the two flours labelled with $2 \mathrm{mg}{ }^{57} \mathrm{Fe}$ as $\mathrm{FeSO}_{4}(1 \mathrm{~B})$, respectively. In study 2 , one test meal was based on the white sorghum flour labelled with $2 \mathrm{mg}{ }^{54} \mathrm{Fe}$ as $\mathrm{FeSO}_{4}$ (2A) and the other two test meals were based on the brown sorghum flour labelled with $2 \mathrm{mg}{ }^{57} \mathrm{Fe}$ as $\mathrm{FeSO}_{4}$ (2B) or with $2 \mathrm{mg}{ }^{58} \mathrm{Fe}$ as NaFeEDTA (2C). In study 3, test meals were based on the brown sorghum flour labelled with $2 \mathrm{mg}{ }^{58} \mathrm{Fe}$ $\mathrm{FeSO}_{4}(3 \mathrm{~A})$, labelled with $2 \mathrm{mg}{ }^{57} \mathrm{Fe}$ as $\mathrm{FeSO}_{4}$ and containing $40 \mathrm{mg}$ AA per serving (3B) or pre-treated with laccase and labelled with $2 \mathrm{mg}{ }^{54} \mathrm{Fe}$ as $\mathrm{FeSO}_{4}(3 \mathrm{C})$.

In all the three studies, test meal servings (235g) were based on $50 \mathrm{~g}$ sorghum flour, $15 \mathrm{~g}$ sugar and $170 \mathrm{~g}$ water. Except for the test meal pre-treated with laccase, test meals were prepared by adding sorghum flour and sugar to previously heated water (about $55^{\circ} \mathrm{C}$ ), and the $\mathrm{pH}$ of the resulting slurry was adjusted to 5.0-5.2 using $0.5 \mathrm{M}$-hydrochloric acid (Sigma-Aldrich). Approximately 3000 phytase units (FTU) $/ 100 \mathrm{~g}$ flour were added to the slurry using the DSM phytase 5000 liquid provided by DSM Nutritional Products, and the slurry was held at about $55^{\circ} \mathrm{C}$ for $1 \mathrm{~h}$ in a water-bath to allow for complete PA degradation. The slurry was then heated to $80^{\circ} \mathrm{C}$ to inactivate phytase. After cooling, water was added to adjust to the ratio of water:sorghum flour of $3 \cdot 4: 1$, and portions corresponding to $50 \mathrm{~g}$ dry weight of sorghum flour were weighed as test meal servings.

The test meal pre-treated with laccase was prepared by adding sorghum flour and sugar to previously heated water (about $40^{\circ} \mathrm{C}$ ) without adjustment of $\mathrm{pH}$. To the slurry, $7-10 \mathrm{ml}$ of phytase and $120 \mathrm{ml}$ of laccase (NS 33136; Novozymes) were added, and the slurry was held at about $40^{\circ} \mathrm{C}$ for $4 \mathrm{~h}$ under continuous stirring in a water-bath to allow for complete PA and partial PP degradation. The slurry was then heated to $80^{\circ} \mathrm{C}$ to inactivate enzymes and processed in the same way as the other test meals mentioned above.

The test meals were prepared in batches, and servings were stored frozen until the day of the consumption. To each test meal serving, shortly before test meal consumption, $2 \mathrm{mg}$ of Fe label in solution were added. With each test meal serving, $250 \mathrm{~g}$ of deionised water were consumed.

\section{Test meal analysis}

The Fe concentrations of the sorghum flours and test meals were determined using graphite-furnace atomic absorption spectrophotometry (AA240Z; Varian) after mineralisation by microwave digestion (MLS ETHOSplus; MLS GmbH). For the estimation of soil contamination, $\mathrm{Al}$ and Ti levels in the sorghum flours were determined by X-ray fluorescence analysis using Spectro X-Lab 2000 (Spectro Analytical Instruments $\mathrm{GmbH}$ ). A matrix correction for food samples was applied. PA concentrations were measured using a modification of the Makower method ${ }^{(30)}$, in which $\mathrm{Fe}$ was replaced by cerium in the precipitation step. After the mineralisation of the precipitates, inorganic phosphate concentrations were determined according to the method of Van Veldhoven \& Mannaerts ${ }^{(31)}$ and converted into PA concentrations. The total PP concentrations of the sorghum flours and test meals were determined using a modified Folin-Ciocalteu method ${ }^{(32)}$, and they are expressed as gallic acid equivalents. Wheat bran (PA assay) and milled beans (PP assay), flushed with Ar to avoid PP oxidation, were analysed together with each series of samples and were used as an internal control material to monitor reproducibility. In vitro accessible Fe concentrations were determined using the method described by Luten et al. ${ }^{(33)}$. This method includes a gastric stage, where the sample is incubated in a $\mathrm{HCl}-$ pepsin solution at $\mathrm{pH} 2$ and $37^{\circ} \mathrm{C}$ for $2 \mathrm{~h}$, followed by an intestinal stage determining dialysability.

\section{Preparation of isotopically labelled iron}

Isotopically labelled ${ }^{54} \mathrm{FeSO}_{4},{ }^{57} \mathrm{FeSO}_{4}$ and ${ }^{58} \mathrm{FeSO}_{4}$ were prepared from isotopically enriched elemental $\mathrm{Fe}\left({ }^{54} \mathrm{Fe}\right.$ metal: 99.9\% enriched; ${ }^{57} \mathrm{Fe}$ metal: $97 \cdot 1 \%$ enriched; ${ }^{58} \mathrm{Fe}$ metal: 99.9\% enriched; all obtained from Chemgas) by dissolution in $0 \cdot 1 \mathrm{M}$-sulphuric acid. The solutions were flushed with $\mathrm{Ar}$ to keep the Fe in the + II oxidation state. The prepared Fe tracer solutions were analysed for Fe isotopic composition and tracer Fe concentration using reverse isotope dilution MS. $\mathrm{Na}^{58} \mathrm{FeEDTA}$ was prepared in solution from ${ }^{58} \mathrm{Fe}$-enriched elemental Fe $\left({ }^{58} \mathrm{Fe}\right.$ metal: $99.9 \%$ enriched; Chemgas). The metal was dissolved in $2 \mathrm{ml}$ of $\mathrm{HCl}$ and diluted with water. The resulting $\mathrm{FeCl}_{3}$ solution was mixed with a freshly prepared aqueous $\mathrm{Na}_{2}$ EDTA solution $\left(\mathrm{Na}_{2}\right.$ EDTA. $\mathrm{H}_{2} \mathrm{O}_{2}$; Sigma Chemical Company) at a molar ratio of 1:1 (Fe:EDTA). The resulting NaFeEDTA solution was added to the test meals.

\section{Blood analysis}

$\mathrm{Hb}$ concentrations were measured using a Coulter Counter (AcT8 Counter; Beckman Coulter); anaemia was defined as $\mathrm{Hb}$ concentrations $<120 \mathrm{~g} / \mathrm{l}^{(34)}$. PF and CRP concentrations were measured using an IMMULITE automatic system (Siemens). ID was defined as PF concentrations $<15 \mu \mathrm{g} / 1$ and ID anaemia as $\mathrm{Hb}$ concentrations $<120 \mathrm{~g} / 1$ and PF concentrations $<15 \mu \mathrm{g} / \mathrm{l}^{(34)}$. High-sensitivity CRP concentrations in healthy individuals were $<5 \mathrm{mg} / \mathrm{l}$.

Each isotopically enriched blood sample was analysed in duplicate for its isotopic composition. Whole blood was 
mineralised by microwave digestion, and Fe was separated by anion-exchange chromatography and a subsequent precipitation step with ammonium hydroxide ${ }^{(35)}$. Fe isotope ratios were determined using a multicollector inductively coupled plasma-MS instrument (NEPTUNE; Thermo Finnigan).

\section{Calculation of the percentage of iron absorption}

The percentages of ${ }^{54} \mathrm{Fe},{ }^{57} \mathrm{Fe}$ and ${ }^{58} \mathrm{Fe}$ labels in the blood were calculated based on the dose of administered isotopes ( $4 \mathrm{mg} / \mathrm{type}$ of test meal), the shift in Fe isotope ratios and the estimated amount of Fe circulating in the body. The amount of circulating Fe was calculated based on the blood volume estimated from height and weight and measured $\mathrm{Hb}$ concentrations $^{(36)}$. The calculations were based on the principles of isotope dilution, taking into account that Fe isotopic labels were not monoisotopic using the method described by Turnlund et al. ${ }^{(37)}$. The calculation of Fe absorption is shown in detail in Fig. S1 (available online). For the calculation of the percentage of absorption, $80 \%$ incorporation of the absorbed Fe into erythrocytes was assumed ${ }^{(38)}$.

\section{Statistical analyses}

Analyses were carried out using the SPSS statistical software (SPSS 19.0; SPSS, Inc.). All values were converted to their logarithms for statistical analyses and reconverted for reporting. The results of the test meal analyses are reported as means and standard deviations. The results of Fe absorption analysis are presented as geometric means with the 95\% CI in parentheses. The results of $\mathrm{Fe}$ status and inflammation measures are presented as means and standard deviations if normally distributed. Medians with 25th-75th percentile ranges in parentheses are used to present results that were not normally distributed after log conversion (CRP and PF). Fe absorption from the different test meals in the same participant was compared using a linear mixed model with repeated measures followed by a post hoc Bonferroni test for multiple comparisons. In the linear mixed model, types of test meal and study day were the fixed effects and individual participant was the random effect. The dependent variable was Fe absorption, and study day was treated as the repeated measure assuming an unstructured covariance type. For the between-study comparison, the same linear mixed model with repeated measures was applied, but study as a fixed effect and $\mathrm{PF}$ as a covariate were added. A one-way ANOVA followed by a post hoc Bonferroni test for multiple comparisons was used for the analysis of participants' baseline characteristics as well as test meal composition (total Fe and PP). Differences were considered significant at $P<0.05$. The studies were powered to detect an intra-subject difference of $30 \%$ in Fe absorption with an $\alpha$-level of 0.05 .

\section{Results}

\section{Participant characteristics}

Among the participants, six (two in study 1, three in study 2 and one in study 3) had ID and three were anaemic (one in each study). ID anaemia was observed in two participants (one each in study 1 and study 2). A slightly elevated CRP concentration $(>3 \mathrm{mg} / \mathrm{l})$ was observed in three women, but none had a CRP concentration $>5 \mathrm{mg} / \mathrm{l}$. None of the variables given in Table 1, except age, differed significantly between the study groups.

\section{Test meal composition}

Uncooked flours from decorticated white and brown sorghum had PP concentrations (expressed as gallic acid equivalents) of 21 (SD 1) $\mathrm{mg}$ and 553 (SD 16) $\mathrm{mg} / 100 \mathrm{~g}$, respectively. The PP concentration of the white sorghum porridge (low PP) was approximately ten and four times lower than that of the brown sorghum porridge (high PP) and that of the porridge based on a mixture of the white and brown sorghum flours (medium PP), respectively $(P<0 \cdot 0001)$ (Table 2$)$. Incubation with laccase reduced $\mathrm{PP}$ concentrations of the brown sorghum test meals by about $75 \%(P<0 \cdot 0001)$. However, laccase did

Table 1. Age, anthropometric features and $\mathrm{Hb}$, plasma ferritin $(\mathrm{PF})$ and $\mathrm{C}$-reactive protein (CRP) concentrations of the participating healthy adult women at baseline (Mean values and standard deviations; medians and 25th and 75th percentiles)

\begin{tabular}{|c|c|c|c|c|c|c|}
\hline & \multicolumn{2}{|c|}{ Study 1 (n 16) } & \multicolumn{2}{|c|}{ Study 2 (n 16) } & \multicolumn{2}{|c|}{ Study 3 ( $n 18$} \\
\hline & Mean & SD & Mean & SD & Mean & SD \\
\hline Age (years) & $24 \cdot 9^{a}$ & $2 \cdot 8$ & $25 \cdot 7^{a}$ & $3 \cdot 2$ & $22 \cdot 1^{b}$ & $3 \cdot 0$ \\
\hline Weight (kg) & $59 \cdot 2$ & $5 \cdot 4$ & $59 \cdot 3$ & $3 \cdot 0$ & $57 \cdot 8$ & $5 \cdot 7$ \\
\hline Height $(\mathrm{cm})$ & 164 & 7 & 166 & 5 & 166 & 6 \\
\hline $\mathrm{BMI}\left(\mathrm{kg} / \mathrm{m}^{2}\right)$ & $22 \cdot 0$ & $2 \cdot 1$ & $21 \cdot 7$ & 1.9 & $21 \cdot 4$ & 1.9 \\
\hline $\mathrm{Hb}(\mathrm{g} / \mathrm{l})$ & 137 & 10 & 135 & 8 & 135 & 7 \\
\hline \multicolumn{7}{|l|}{$P F(\mu g / l)$} \\
\hline Median & \multicolumn{2}{|c|}{$57 \cdot 8$} & \multicolumn{2}{|c|}{31.4} & \multicolumn{2}{|c|}{$43 \cdot 2$} \\
\hline 25th-75th percentile & \multicolumn{2}{|c|}{$36 \cdot 6-86 \cdot 6$} & \multicolumn{2}{|c|}{$20 \cdot 6-45 \cdot 1$} & \multicolumn{2}{|c|}{$27 \cdot 8-52 \cdot 0$} \\
\hline \multicolumn{7}{|l|}{ Plasma CRP (mg/l) } \\
\hline Median & \multicolumn{2}{|c|}{0.4} & \multicolumn{2}{|c|}{$1 \cdot 3$} & \multicolumn{2}{|c|}{0.3} \\
\hline 25th-75th percentile & \multicolumn{2}{|c|}{$0.2-0.9$} & \multicolumn{2}{|c|}{$0 \cdot 2-2 \cdot 0$} & \multicolumn{2}{|c|}{$0.2-0.6$} \\
\hline
\end{tabular}

${ }^{\mathrm{a}, \mathrm{b}}$ Mean values within a row with unlike superscript letters were significantly different $(P<0.05)$. 
Table 2. Composition of different sorghum test meals based on $50 \mathrm{~g}$ of flour and consumed by the healthy adult women

(Mean values and standard deviations)

\begin{tabular}{|c|c|c|c|c|c|c|c|c|c|c|}
\hline \multirow[b]{2}{*}{ Meals } & \multirow[b]{2}{*}{$\begin{array}{l}\text { Description } \\
\text { (Fe compound) }\end{array}$} & \multicolumn{2}{|c|}{$\begin{array}{c}\mathrm{PP}^{*} \\
\text { (mg/serving) }\end{array}$} & \multicolumn{2}{|c|}{$\begin{array}{c}\text { PA† } \\
\text { (mg/serving) }\end{array}$} & \multicolumn{2}{|c|}{$\begin{array}{c}\text { Total Feł } \\
\text { (mg/serving) }\end{array}$} & \multirow{2}{*}{$\begin{array}{c}\text { Native } \\
\text { Fe§ } \\
\text { (mg/serving) }\end{array}$} & \multirow{2}{*}{$\begin{array}{c}\text { Contamination } \\
\text { Fe§ } \\
\text { (mg/serving) }\end{array}$} & \multirow{2}{*}{$\begin{array}{l}\text { Fortification } \\
\text { Fe\|l } \\
\text { (mg/serving) }\end{array}$} \\
\hline & & Mean & SD & Mean & SD & Mean & SD & & & \\
\hline $1 \mathrm{~A}$ and $2 \mathrm{~A}$ & $\begin{array}{l}\text { Low-PP sorghum } \\
\text { porridges }\left(\mathrm{FeSO}_{4}\right)\end{array}$ & $17^{a}$ & 1 & \multicolumn{2}{|c|}{ ND } & $3.6^{\mathrm{a}}$ & 0.1 & 1.6 & - & $2 \cdot 0$ \\
\hline 1B & $\begin{array}{l}\text { Medium-PP sorghum } \\
\text { porridge }\left(\mathrm{FeSO}_{4}\right)\end{array}$ & $73^{b}$ & 1 & \multicolumn{2}{|c|}{ ND } & $4 \cdot 0^{a, b}$ & 0.2 & $1 \cdot 1$ & 0.9 & $2 \cdot 0$ \\
\hline $\begin{array}{l}1 \mathrm{C}, 2 \mathrm{~B} \\
\text { and } 3 \mathrm{~A}\end{array}$ & $\begin{array}{l}\text { High-PP sorghum } \\
\text { porridges }\left(\mathrm{FeSO}_{4}\right)\end{array}$ & $167^{c}$ & 8 & \multicolumn{2}{|c|}{ ND } & $5 \cdot 0^{b}$ & 0.7 & $1 \cdot 1$ & 1.9 & $2 \cdot 0$ \\
\hline $2 \mathrm{C}$ & $\begin{array}{l}\text { High-PP sorghum } \\
\text { porridge (NaFeEDTA) }\end{array}$ & $167^{c}$ & 8 & \multicolumn{2}{|c|}{ ND } & $5 \cdot 0^{b}$ & 0.7 & 1.1 & 1.9 & $2 \cdot 0$ \\
\hline 3B & $\begin{array}{l}\text { High-PP sorghum } \\
\text { porridge }+40 \mathrm{mg} \\
\mathrm{AA}\left(\mathrm{FeSO}_{4}\right)\end{array}$ & $167^{c}$ & 8 & \multicolumn{2}{|c|}{ ND } & $5 \cdot 0^{b}$ & 0.7 & $1 \cdot 1$ & 1.9 & $2 \cdot 0$ \\
\hline $3 C$ & $\begin{array}{l}\text { Reduced-PP sorghum } \\
\text { porridge, pre-treated } \\
\text { with laccase }\left(\mathrm{FeSO}_{4}\right)\end{array}$ & $42^{d}$ & 1 & \multicolumn{2}{|c|}{ ND } & $5 \cdot 1^{b}$ & 0.1 & 1.1 & 1.9 & $2 \cdot 0$ \\
\hline
\end{tabular}

PP, polyphenol; PA, phytic acid; ND, not detectable; AA, ascorbic acid.

a,b,c,d Mean values within a column with unlike superscript letters were significantly different (PP: $P<0.0001 ; \mathrm{Fe}: P<0.05)$.

${ }^{\star} n 3$ independent analyses. Expressed as gallic acid equivalents.

$\dagger \mathrm{ND}$, below the limit of detection ( $<8 \mathrm{mg} / \mathrm{serving}), n 3$ independent analyses.

$\ddagger n 3$ independent analyses for the prepared sorghum porridges.

$\S$ The calculation of native and contamination Fe concentrations is based on the measured Fe concentrations of the flours of washed (non-contaminated) and unwashed (contaminated) brown sorghum grains: 2.1 (SD 0.1 ) $\mathrm{mg} / 100 \mathrm{~g}$ and 5.8 (SD 0.4 ) $\mathrm{mg} / 100 \mathrm{~g}$, respectively.

$\| 2 \mathrm{mg} \mathrm{Fe}$ added as ${ }^{54} \mathrm{Fe},{ }^{57} \mathrm{Fe}$ or ${ }^{58} \mathrm{Fe}$ in the form of $\mathrm{FeSO}_{4}$ or $\mathrm{NaFeEDTA}$.

not completely degrade PP, and we were not able to attain a further PP reduction, as measured by the Folin-Ciocalteu method, by modifying the incubation conditions (time, temperature and $\mathrm{pH})$. PA concentrations were below the detection limit in all the test meals ( $<8 \mathrm{mg} /$ test meal serving).

The Fe concentration of the white sorghum flour was 2.6 (sD 0.3$) \mathrm{mg} / 100 \mathrm{~g}$. The total Fe concentration of the brown sorghum flour used for the preparation of the test meals was $5.8(\mathrm{sD} 0.4) \mathrm{mg} / 100 \mathrm{~g}$, whereas native Fe concentration was $2 \cdot 1$ (SD $0 \cdot 1) \mathrm{mg} / 100 \mathrm{~g}$ and contamination Fe concentration was about $3.7 \mathrm{mg} / 100 \mathrm{~g}$. The native $\mathrm{Fe}$ concentration of the brown sorghum flour was obtained by analysing the Fe concentration of brown sorghum grains that, in contrast to the grains used to obtain the bulk of flour, were carefully washed after decortication. Fe contamination of the brown sorghum flour was confirmed by the small silver spots detected on the magnetic stirrer after the incubation of the flour with laccase. The amount of contamination $\mathrm{Fe}$ was about $0.9 \mathrm{mg} /$ portion in the test meals based on the white and brown sorghum flours (meal 1B), and it was about $1.9 \mathrm{mg} /$ portion in the test meals based on the brown sorghum flour (meals 1C, 2B, 2C, 3A, 3B and 3C). The total Fe concentrations and the proportion of different $\mathrm{Fe}$ sources in the different test meals are given in Table 2 .

The $\mathrm{Al}$ concentrations of the non-contaminated and contaminated grains were 4.9 (SD 1.4$) \mathrm{mg} / 100 \mathrm{~g}$ and 3.0 (SD $1.6 \mathrm{mg}) / 100 \mathrm{~g}$, respectively, and $\mathrm{Ti}$ concentrations of the non-contaminated and contaminated grains were below the detection limit $(0.5 \mathrm{mg} / 100 \mathrm{~g})$. The in vitro accessible $\mathrm{Fe}$ concentrations of the non-contaminated and contaminated flours after in vitro gastric digestion followed by a dialysability procedure were 578 (SD 87) $\mu \mathrm{g} / 100 \mathrm{~g}$ and 608 (SD 30) $\mu \mathrm{g} / 100 \mathrm{~g}$, respectively, indicating that the contamination $\mathrm{Fe}$ was not soluble during simulated gastric digestion and/or dialysable.

\section{Iron absorption measurements}

In study 1 , the mean percentage of Fe absorption from the medium-PP and high-PP sorghum meals was approximately three times lower $(P<0.001)$ than that from the low-PP sorghum meals (Table 3). There was no difference in Fe absorption $(P=0.9)$ between the medium-PP and high-PP sorghum meals. In study $2, \mathrm{Fe}$ absorption from the $\mathrm{FeSO}_{4}$ fortified low-PP sorghum meals was four and $2 \cdot 3$ times higher $(P<0.001)$ than that from the $\mathrm{FeSO}_{4-}$ or NaFeEDTAfortified high-PP sorghum meals, respectively. However, Fe absorption from the high-PP sorghum meals fortified with NaFeEDTA was almost 2-fold higher than that from the highPP sorghum meals fortified with $\mathrm{FeSO}_{4}(P<0 \cdot 001)$. In study 3 , the mean percentage of Fe absorption from the high-PP sorghum meals with added AA was almost 3-fold higher than that from the high-PP sorghum meals without AA $(P<0 \cdot 001)$. Decreasing the concentrations of PP of high-PP sorghum meals by laccase pre-treatment did not increase Fe absorption compared with that from the high-PP sorghum meals without laccase pre-treatment $(P=0 \cdot 4)$. Regarding the between-study comparison (Fig. 2), Fe absorption from meals containing $167 \mathrm{mg}$ PP per serving fortified either with $\mathrm{FeSO}_{4}$ (meals 1C, $2 \mathrm{~B}$ and $3 \mathrm{~A}$ ) or with NaFeEDTA (meal 2C) was different $(P<0 \cdot 05)$, but absorption from the latter was not different 
Table 3. Percentage of iron absorption from different sorghum test meals fortified with ferrous sulphate or sodium iron EDTA in the healthy adult women

(Geometric means and $95 \% \mathrm{Cl}$ )

\begin{tabular}{|c|c|c|c|c|}
\hline \multirow[b]{2}{*}{ Study no. } & \multirow[b]{2}{*}{$n$} & \multirow[b]{2}{*}{ Meals } & \multicolumn{2}{|c|}{ Fe absorption (\%) } \\
\hline & & & Geometric mean & $95 \% \mathrm{Cl}$ \\
\hline \multirow[t]{3}{*}{ Study 1} & \multirow[t]{3}{*}{16} & $1 \mathrm{~A}-$ low-PP sorghum porridge $\left(\mathrm{FeSO}_{4}\right)$ & $8 \cdot 5^{\mathrm{a}}$ & $5 \cdot 4,13 \cdot 4$ \\
\hline & & $1 \mathrm{~B}$ - medium-PP sorghum porridge $\left(\mathrm{FeSO}_{4}\right)$ & $3 \cdot 2^{b}$ & $1 \cdot 7,5 \cdot 9$ \\
\hline & & $1 \mathrm{C}-$ high-PP sorghum porridge $\left(\mathrm{FeSO}_{4}\right)$ & $2 \cdot 7^{\mathrm{b}}$ & $1 \cdot 5,5 \cdot 0$ \\
\hline \multirow[t]{3}{*}{ Study 2} & \multirow[t]{3}{*}{16} & $2 \mathrm{~A}$ - low-PP sorghum porridge $\left(\mathrm{FeSO}_{4}\right)$ & $10 \cdot 7^{\mathrm{a}}$ & $7 \cdot 2,15 \cdot 9$ \\
\hline & & 2B - high-PP sorghum porridge $\left(\mathrm{FeSO}_{4}\right)$ & $2 \cdot 7^{\mathrm{b}}$ & $1.5,5 \cdot 0$ \\
\hline & & $2 \mathrm{C}$ - high-PP sorghum porridge (NaFeEDTA) & $4 \cdot 6^{\mathrm{C}}$ & $2 \cdot 6,8 \cdot 0$ \\
\hline \multirow[t]{3}{*}{ Study 3} & \multirow[t]{3}{*}{18} & $3 \mathrm{~A}$ - high-PP sorghum porridge $\left(\mathrm{FeSO}_{4}\right)$ & $4 \cdot 6^{\mathrm{a}}$ & $3 \cdot 3,6 \cdot 5$ \\
\hline & & $3 \mathrm{~B}-$ high-PP sorghum porridge $+\mathrm{AA}\left(\mathrm{FeSO}_{4}\right)$ & $13 \cdot 6^{\mathrm{b}}$ & $9 \cdot 9,18 \cdot 7$ \\
\hline & & $3 \mathrm{C}$ - reduced-PP sorghum porridge, pre-treated with laccase $\left(\mathrm{FeSO}_{4}\right)$ & $4 \cdot 8^{\mathrm{a}}$ & $3 \cdot 5,6 \cdot 6$ \\
\hline
\end{tabular}

from that from the $\mathrm{FeSO}_{4}$-fortified meals containing $72 \mathrm{mg} \mathrm{PP}$ $(P=0 \cdot 8)$ or the laccase pre-treated meals ( $42 \mathrm{mg} P P ; P=0 \cdot 06)$. The between-study comparison of meals based on the white sorghum flour (meals $1 \mathrm{~A}$ and $2 \mathrm{~A}$ ) and the AA-fortified meal based on the brown sorghum (meal 3B) showed no difference in Fe absorption $(P=1 \cdot 0)$.

\section{Discussion}

In study 1 , we observed that $73 \mathrm{mg}$ and $167 \mathrm{mg}$ of PP in brown sorghum, expressed as gallic acid equivalents, significantly decreased the absorption of fortification Fe from standardised dephytinised sorghum porridges. These results indicate that Fe bioavailability from traditional Western African porridges based on red or brown sorghum, containing $80-160 \mathrm{mg}$ of $\mathrm{PP}^{(9)}$, would be expected to be impaired even if most of the PA is degraded by fermentation. However, it should be noted that we used standardised dephytinised test meals, and the effect of PP on Fe absorption might be differently pronounced in composite, non-dephytinised, sorghum-based meals. In a study with beans, the inhibitory effect of PP has only been observed in standardised bean meals but not in composite bean meals containing different enhancers and inhibitors ${ }^{(39)}$.

Brown sorghum PP seem to be slightly less inhibitory than black tea PP, since Hurrell et al. ${ }^{(19)}$ reported that 100 and $200 \mathrm{mg}$ gallic acid equivalents of black tea PP reduced Fe absorption from an Fe-fortified bread meal by about $80 \%$. The inhibitory effect of sorghum PP in the present study was similar to that of herb tea $\mathrm{PP}^{(19)}$, but markedly greater than the inhibitory effect of common bean $\mathrm{PP}^{(40)}$. The reason for these differences in the inhibitory potential of PP from different food sources is the different PP structures, which lead to different Fe-binding properties ${ }^{(20,21)}$. The structures responsible for the inhibitory effect observed in

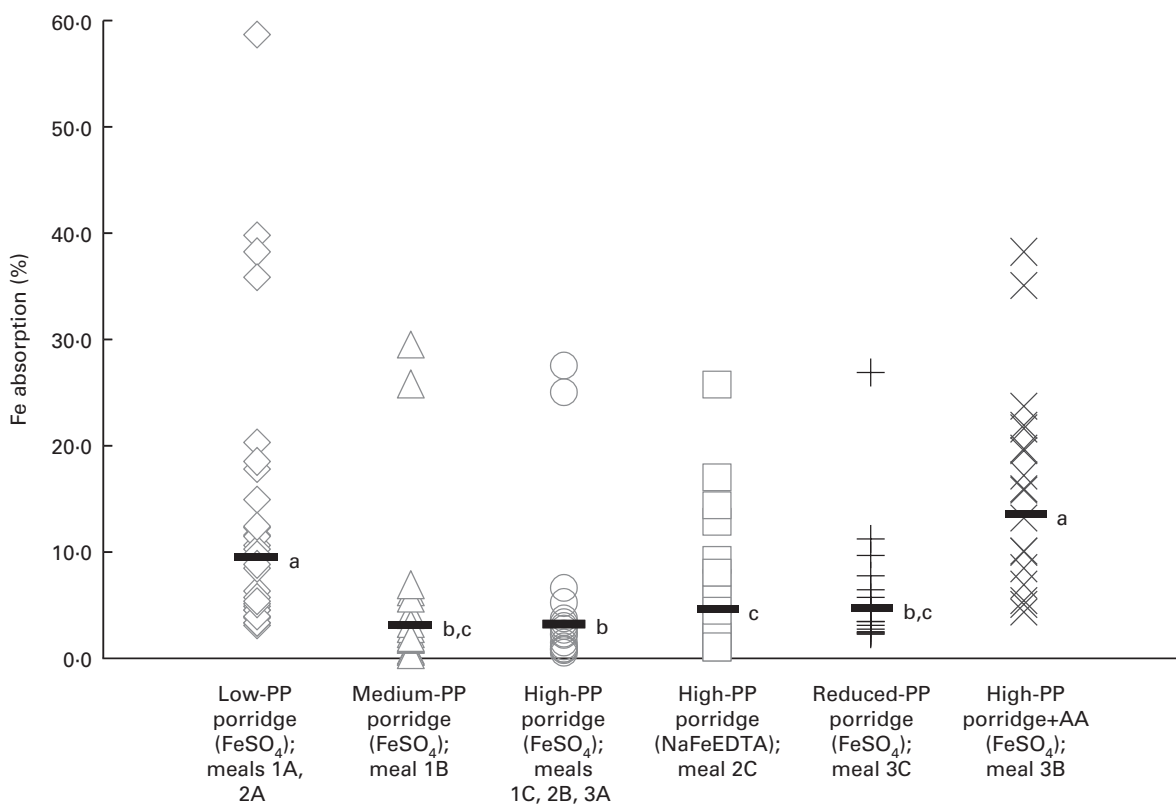

Fig. 2. Between-study comparison of iron absorption from the different types of sorghum porridges consumed by healthy adult women. Values are individual data points, with the horizontal bar representing the geometric mean. Absorption data from the same type of meals given in the different studies (meals $1 \mathrm{~A}$ and $2 \mathrm{~A}$, $n$ 32; meals $1 \mathrm{C}, 2 \mathrm{~B}$ and $3 \mathrm{~A}, n 50)$ were combined for the statistical analyses. ${ }^{\mathrm{a}, \mathrm{b}, \mathrm{c}}$ Values with unlike letters were significantly different $(P<0.05)$. PP, polyphenol; $\mathrm{AA}$, ascorbic acid. 
the present study are most probably catechol and galloyl groups of condensed tannins, which represent $72 \%$ of the PP compounds found in the brown sorghum variety used in the present study (Framida) ${ }^{(7)}$. Red or brown sorghum has been reported to contain high amounts of catechols and galloyls (1350 and $550 \mathrm{mg} / 100 \mathrm{~g}$ grain, respectively) ${ }^{(17)}$, which can form strong, non-absorbable complexes with $\mathrm{Fe}$ in the intestinal tract ${ }^{(19,20)}$. The fact that Fe absorption from the medium-PP sorghum meals was as low as that from the high-PP sorghum meals suggests that relatively low amounts of these condensed tannins in Framida sorghum can strongly inhibit $\mathrm{Fe}$ absorption. The white sorghum contained very little PP and did not have a pigmented testa, indicating that it does not contain condensed tannins. We assume that there was little or no significant interference with $\mathrm{Fe}$ absorption from white sorghum porridges.

The results of the present study are in agreement with those of a previous radioisotope study reporting 2-fold higher Fe absorption from a low-PP sorghum variety than from a highPP sorghum variety ${ }^{(41)}$, but contradictory to those of an early radioisotope study reporting similar Fe absorption from a lowand a high-tannin sorghum variety ${ }^{(42)}$. In both studies, the different PA concentrations of the two sorghum varieties make interpretation difficult. More recently, Hurrell et al. ${ }^{(25)}$ have reported that dephytinisation of low-tannin sorghum meals increases Fe absorption by 2 -fold, but that no improvement in Fe absorption can be observed after dephytinisation of hightannin sorghum meals. In all the three previous studies, the exact concentrations of PP in the test meals are unknown because PP measurements were made before cooking, which is known to significantly decrease PP concentrations ${ }^{(43,44)}$.

The results of study 2 using NaFeEDTA confirmed the earlier reports that EDTA cannot completely protect Fe from PP binding ${ }^{(27,45)}$. Presumably at the $\mathrm{pH}$ of the stomach, PP (but not PA) can still strongly compete with EDTA for Fe binding. Sorghum foods are usually not completely dephytinised and contain considerable amounts of $\mathrm{PA}^{(44)}$. NaFeEDTA is known to overcome the inhibitory effect of $\mathrm{PA}^{(27)}$; thus, it seems to be a suitable compound for the fortification of sorghum flour containing both inhibitors. A previous study using NaFeEDTA as a fortificant for fermented red sorghum flour with moderate concentrations of PP and PA has reported high Fe absorption of about $18 \%$ in women treated for malaria ${ }^{(46)}$.

The enhancing effect of AA on Fe absorption in study 3, completely overcoming the inhibitory effect of PP, can be attributed to its ability to reduce ferric Fe to ferrous $\mathrm{Fe}$ in the stomach and duodenum and to form soluble complexes with ferric and ferrous $\mathrm{Fe}$ at a higher $\mathrm{pH}$ in the intestine ${ }^{(47)}$. Fe that is bound to AA can no longer bind to PP, and ferrous Fe forms much weaker complexes with PP compared with ferric $\mathrm{Fe}^{(48)}$. The present results are in agreement with those of a previous study, which showed that AA prevents the dose-dependent inhibitory effect of the PP compound tannic $\operatorname{acid}^{(49)}$. The addition of AA to high-PP sorghum foods fortified with Fe would appear to be a useful approach to increase Fe bioavailability, but the heat and oxidation sensitivity of AA is a disadvantage and has to be considered.
It was somewhat surprising that the enzymatic reduction of total PP in sorghum porridges by laccase did not increase Fe absorption. Enhanced absorption was predicted by an in vitro study, which reported increased in vitro accessible Fe concentrations after PP reduction in dephytinised high-tannin sorghum ${ }^{(50)}$. The in vitro study, however, used tyrosinase instead of laccase as the PPO and whole red sorghum grains with a much higher initial PP concentration than that of the decorticated sorghum in the present study. We used laccase as the PPO because, in terms of PP degradation, tyrosinase did not perform well in preliminary trials. Furthermore, tyrosinase is not suitable for human food applications, as there is currently no food-grade product available. Food-grade laccase is an enzyme that catalyses the oxidation of a wide range of phenolic substrates including ortho- and para-diphenols and triphenols. Tyrosinase preferably oxidises monophenols and a few diphenols ${ }^{(51)}$. We had assumed that laccase would oxidise the catechol groups and, as these groups are suspected to bind to Fe, increase absorption. However, the present results indicate that laccase did not degrade or only partly degraded the inhibitory PP in the brown sorghum porridge. It seems that the remaining unchanged PP ( $42 \mathrm{mg} /$ serving) are still strongly inhibitory and/or that the transformed PP can still bind to Fe. Although the present study did not find laccase to be useful to improve Fe absorption, more systematic studies with laccase and other PPO are needed to evaluate further possibilities.

Some test meals used in the present study contained contamination $\mathrm{Fe}$ (about $23 \%$ and about $38 \%$ of total $\mathrm{Fe}$ ). We can rule out that this Fe came from soil contamination because the grains were carefully washed before decortication and because soil-contaminated grains would have higher $\mathrm{Al}$ and $\mathrm{Ti}$ concentrations than those found in the grains used in the present study ${ }^{(52)}$. Contamination from milling can also be excluded because the centrifugal mill was constructed with Ti. Therefore, iron contamination might have resulted from the decorticator made of stainless steel. Based on the present results of simulated gastric digestion followed by dialysis, which showed that the quantity of in vitro accessible Fe was identical for non-contaminated and contaminated sorghum grains, we conclude that the Fe in stainless steel is not bioavailable or at best poorly bioavailable. Nevertheless, if significant amounts of the contaminant steel Fe have dissolved and entered the common Fe pool in the three Fe absorption studies, our data for the percentage of Fe absorption would slightly underestimate the inhibitory effect of PP because the additional bioavailable Fe from steel would lead to a lower molar ratio of PP:Fe, which could result in a higher percentage of absorption from the isotopic tag. Therefore, we conclude that the contamination Fe present in some sorghum meals would not be expected to greatly influence the measured percentage of absorption values or change the conclusion on the extent to which sorghum PP inhibit Fe absorption.

In conclusion, the three Fe absorption studies show that brown sorghum PP are strong inhibitors of Fe absorption. They appear to be more inhibitory than bean PP and similar to herb tea PP. This means that dephytinisation of meals, based on coloured sorghum varieties, is unlikely to greatly 
increase $\mathrm{Fe}$ absorption as does dephytinisation of other cereals ${ }^{(25)}$. AA is the preferred enhancer of $\mathrm{Fe}$ absorption from sorghum meals as this overcomes the inhibition of both PP and PA, whereas the use of NaFeEDTA is much more effective against PA than against PP. Reduction of PP by PPO appears to be possible, and this treatment merits more investigation.

\section{Supplementary material}

To view supplementary material for this article, please visit http://dx.doi.org/10.1017/S0007114513002705

\section{Acknowledgements}

The authors thank Claire Monquet-Rivier (Institute de Recherche pour le Développement, Montpellier, France), Laurencia Toulsoumdé Ouattara (Centre National de la Recherche Scientifique et Technologique, Ouagadougou, Burkina Faso) and Eva Weltzien (International Crops Research Institute for the Semi-Arid Tropics, Bamako, Mali) for providing the sorghum varieties and for the decortication of sorghum. They also thank DSM Nutritional Products (Basel, Switzerland) and Novozymes (Dittingen, Switzerland) for donating the phytase and laccase, respectively.

The present study was supported by the INSTAPA project, which receives funding from the European Community's Seventh Framework Programme [FP7/2007-2013] under grant agreement no. 211484. The Seventh Framework Programme of the European Community had no role in the design and analysis of the study or in the writing of this article.

The authors' contributions are as follows: C. I. C., I. M. E., C. Z. and R. F. H. designed the research; C. I. C., I. M. E. and C. Z. conducted the research; C. I. C. and C. Z. analysed the data; C. I. C., I. M. E. and R. F. H. wrote the paper; C. I. C., I. M. E. and R. F. H. had primary responsibility for the final content. All authors read and approved the final version of the paper. None of the authors declares any conflict of interest.

\section{References}

1. McLean E, Cogswell M, Egli I, et al. (2009) Worldwide prevalence of anaemia, WHO Vitamin and Mineral Nutrition Information System, 1993-2005. Public Health Nutr 12, $444-454$

2. Zimmermann MB \& Hurrell RF (2007) Nutritional iron deficiency. Lancet 370, 511-520.

3. Aikawa R, Ngyen CK, Sasaki S, et al. (2006) Risk factors for iron-deficiency anaemia among pregnant women living in rural Vietnam. Public Health Nutr 9, 443-448.

4. Zimmermann MB, Chaouki N \& Hurrell RF (2005) Iron deficiency due to consumption of a habitual diet low in bioavailable iron: a longitudinal cohort study in Moroccan children. Am J Clin Nutr 81, 115-121.

5. Rooney LW \& Waniska RD (2000) Sorghum food and industrial utilization. In Origin, History, Technology, and Production, pp. 689-729 [CW Smith and RA Frederiksen, editors]. New York, NY: John Wiley and Sons.
6. Godwin ID \& Gray SJ (2000) Overcoming productivity and quality constraints in sorghum: the role for genetic engineering. In Transgenic Cereals, pp. 153-177 [L O'Brien and RJ Henry, editors]. St. Paul, MN: American Association of Cereal Chemists.

7. Dicko MH, Hilhorst R, Gruppen H, et al. (2002) Comparison of content in phenolic compounds, polyphenol oxidase, and peroxidase in grains of fifty sorghum varieties from Burkina Faso. J Agric Food Chem 50, 3780-3788.

8. Anglani C (1998) Sorghum for human food - a review. Plant Food Hum Nutr 52, 85-95.

9. Kayode APP, Adegbidi A, Hounhouigan JD, et al. (2005) Quality of farmers' varieties of sorghum and derived foods as perceived by consumers in Benin. Ecol Food Nutr 44, 271-294.

10. Badi S, Pedersen B, Monowar L, et al. (1990) The nutritive value of new and traditional sorghum and millet foods from Sudan. Plant Food Hum Nutr 40, 5-19.

11. Onofiok NO \& Nnanyelugo DO (1998) Weaning foods in West Africa: nutritional problems and possible solutions. Food Nutr Bull 19, 27-33(7).

12. Igbedioh SO, Ogbeni AO \& Adole GM (1996) Infant weaning practices of some Tiv women resident in Makurdi, Nigeria. Nutr Health 11, 13-28.

13. Kayode AP, Nout MJ, Bakker EJ, et al. (2006) Evaluation of the simultaneous effects of processing parameters on the iron and zinc solubility of infant sorghum porridge by response surface methodology. J Agric Food Chem 54, 4253-4259.

14. Mitchikpe ECS, Dossa RAM, Ategbo EAD, et al. (2008) The supply of bioavailable iron and zinc may be affected by phytate in Beninese children. J Food Compos Anal 21, 17-25.

15. Kayode AP, Linnemann AR, Hounhouigan JD, et al. (2006) Genetic and environmental impact on iron, zinc, and phytate in food sorghum grown in Benin. J Agric Food Chem $\mathbf{5 4}$, $256-262$.

16. Makokha AO, Oniang'o RK, Njoroge SM, et al. (2002) Effect of traditional fermentation and malting on phytic acid and mineral availability from sorghum (Sorghum bicolor) and finger millet (Eleusine coracana) grain varieties grown in Kenya. Food Nutr Bull 23, 241-245.

17. Towo EE, Svanberg U \& Ndossi GD (2003) Effect of grain pre-treatment on different extractable phenolic groups in cereals and legumes commonly consumed in Tanzania. J Sci Food Agric 83, 980-986.

18. Hallberg L, Rossander L \& Skanberg AB (1987) Phytates and the inhibitory effect of bran on iron absorption in man. Am J Clin Nutr 45, 988-996.

19. Hurrell RF, Reddy M \& Cook JD (1999) Inhibition of nonhaem iron absorption in man by polyphenolic-containing beverages. Br J Nutr 81, 289-295.

20. Brune M, Rossander L \& Hallberg L (1989) Iron absorption and phenolic compounds: importance of different phenolic structures. Eur J Clin Nutr 43, 547-557.

21. Tuntipopipat S, Judprasong K, Zeder C, et al. (2006) Chili, but not turmeric, inhibits iron absorption in young women from an iron-fortified composite meal. J Nutr 136, 2970-2974.

22. Hahn DH \& Rooney LW (1986) Effect of genotype on tannins and phenols of sorghum. Cereal Chem 63, 4-8.

23. Dykes L \& Rooney LW (2006) Sorghum and millet phenols and antioxidants. J Cereal Sci 44, 236-251.

24. Dykes L, Rooney LW, Waniska RD, et al. (2005) Phenolic compounds and antioxidant activity of sorghum grains of varying genotypes. J Agric Food Chem 53, 6813-6818. 
25. Hurrell RF, Reddy MB, Juillerat MA, et al. (2003) Degradation of phytic acid in cereal porridges improves iron absorption by human subjects. Am J Clin Nutr 77, 1213-1219.

26. Hurrell R, Ranum P, de Pee S, et al. (2010) Revised recommendations for iron fortification of wheat flour and an evaluation of the expected impact of current national wheat flour fortification programs. Food Nutr Bull 31, $\mathrm{S} 7-\mathrm{S} 21$.

27. Hurrell RF, Reddy MB, Burri J, et al. (2000) An evaluation of EDTA compounds for iron fortification of cereal-based foods. Br J Nutr 84, 903-910.

28. Hallberg L, Brune M \& Rossander L (1989) Iron-absorption in man - ascorbic-acid and dose-dependent inhibition by phytate. Am J Clin Nutr 49, 140-144.

29. Walczyk T, Davidsson L, Zavaleta N, et al. (1997) Stable isotope labels as a tool to determine the iron absorption by Peruvian school children from a breakfast meal. Fresen J Anal Chem 359, 445-449.

30. Makower RU (1970) Extraction and determination of phytic acid in beans (Phaseolus vulgaris). Cereal Chem 47, 288-296.

31. Van Veldhoven PP \& Mannaerts GP (1987) Inorganic and organic phosphate measurements in the nanomolar range. Anal Biochem 161, 45-48.

32. Singleton VL \& Rossi JA (1965) Colorimetry of total phenolics with phosphomolybdic-phosphotungstic acid reagents. Am J Enol Viticult 16, 144-158.

33. Luten J, Crews H, Flynn A, et al. (1996) Interlaboratory trial on the determination of the in vitro iron dialysability from food. I Sci Food Agric 72, 415-424.

34. World Health Organization (2001) Iron Deficiency Anemia: Assessment, Prevention and Control. Geneva: WHO.

35. Hotz K, Krayenbuehl PA \& Walczyk T (2012) Mobilization of storage iron is reflected in the iron isotopic composition of blood in humans. J Biol Inorg Chem 17, 301-309.

36. Brown E, Hopper J Jr, Hodges JL Jr, et al. (1962) Red cell, plasma, and blood volume in the healthy women measured by radiochromium cell-labeling and hematocrit. J Clin Invest 41, 2182-2190.

37. Turnlund JR, Keyes WR \& Peiffer GL (1993) Isotope ratios of molybdenum determined by thermal ionization massspectrometry for stable-isotope studies of molybdenum metabolism in humans. Anal Chem 65, 1717-1722.

38. Barrett JF, Whittaker PG, Williams JG, et al. (1992) Absorption of non-haem iron in normal women measured by the incorporation of two stable isotopes into erythrocytes. Clin Sci (Lond) 83, 213-219.

39. Petry N, Egli I, Gahutu JB, et al. (2012) Stable iron isotope studies in Rwandese women indicate that the common bean has limited potential as a vehicle for iron biofortification. J Nutr 142, 492-497.

40. Petry N, Egli I, Zeder C, et al. (2010) Polyphenols and phytic acid contribute to the low iron bioavailability from common beans in young women. J Nutr 140, 1977-1982.

41. Gillooly M, Bothwell TH, Charlton RW, et al. (1984) Factors affecting the absorption of iron from cereals. Br J Nutr $\mathbf{5 1}$, $37-46$.

42. Radhakrishnan MR \& Sivaprasad J (1980) Tannin content of sorghum varieties and their role in iron bioavailability. J Agric Food Chem 28, 55-57.

43. Awika JM, Dykes L, Gu L, et al. (2003) Processing of sorghum (Sorghum bicolor) and sorghum products alters procyanidin oligomer and polymer distribution and content. J Agric Food Chem 51, 5516-5521.

44. Kayode APP, Linnemann AR, Nout MJR, et al. (2007) Impact of sorghum processing on phytate, phenolic compounds and in vitro solubility of iron and zinc in thick porridges. $J$ Sci Food Agric 87, 832-838

45. Macphail AP, Bothwell TH, Torrance JD, et al. (1981) Factors affecting the absorption of iron from Fe(III) EDTA. BrJ Nutr 45, 215-227.

46. Cercamondi CI, Egli IM, Ahouandjinou E, et al. (2010) Afebrile Plasmodium falciparum parasitemia decreases absorption of fortification iron but does not affect systemic iron utilization a double stable-isotope study in young Beninese women. Am J Clin Nutr 92, 1385-1392.

47. Rossander-Hulthén L \& Hallberg L (1996) Dietary factors influencing iron absorption - an overview. In Iron Nutrition in Health and Disease [L Hallberg, editor]. London: John Libbey \& Company.

48. Perron NR \& Brumaghim JL (2009) A review of the antioxidant mechanisms of polyphenol compounds related to iron binding. Cell Biochem Biophys 53, 75-100.

49. Siegenberg D, Baynes RD, Bothwell TH, et al. (1991) Ascorbic-acid prevents the dose-dependent inhibitory effects of polyphenols and phytates on nonheme-iron absorption. Am J Clin Nutr 53, 537-541.

50. Matuschek E, Towo E \& Svanberg U (2001) Oxidation of polyphenols in phytate-reduced high-tannin cereals: effect on different phenolic groups and on in vitro accessible iron. J Agric Food Chem 49, 5630-5638.

51. Aniszewski T, Lieberei R \& Gulewicz K (2008) Research on catecholases, laccases and cresolases in plants. Recent progress and future needs. Acta Biol Cracov Bot 50, 7-18.

52. Stangoulis J, Sison C (2008) Crop sampling protocols for micronutrient analysis. HarvestPlus Technical Monograph Series. http://www.ifpri.org/sites/default/files/publications/ tech07.pdf (accessed January 2013). 